\title{
Measurement Practices for Knowledge Management: An Option Perspective
}

\author{
An-Pin Chen and Mu-Yen Chen \\ Institute of Information Management, National Chiao Tung University, \\ Hsinchu, 300, Taiwan, ROC \\ \{apc, mychen\}@iim.nctu.edu.tw
}

\begin{abstract}
This article develops an option pricing model to evaluate knowledge management (KM) activities from the following perspectives: knowledge creation, knowledge conversion, knowledge circulation, and knowledge carry out. This paper makes three important contributions: (1) it provides a formal theoretical grounding for the validity of the Black-Scholes model that might be employed to KM; (2) it proposes a measurement framework to enable leveraging knowledge assets effectively and efficiently; (3) it presents the first application of the Black-Scholes model that uses a real world business situation involving $\mathrm{KM}$ as its test bed. The results prove the option pricing model can be act as a measurement guideline to the whole KM activities.
\end{abstract}

\section{Introduction}

In a knowledge economy where the only certainty is uncertainty, one source of lasting competitive advantage is knowledge and its manipulation [26]. Today, there is a growing recognition by researchers and practitioners about the importance of managing knowledge as a critical source for competitive advantage. As the resource commitments to knowledge management $(\mathrm{KM})$ continue to escalate, the following types of questions are being asked more frequently than ever before: Is that investment in $\mathrm{KM}$ really worthwhile? Is that KM we implemented a success? Is our KM productive and effective?

Recent surveys indicate that issues such as 'measuring the value of KM' and 'evaluating KM performance' are of great importance to managers in places like Asia [1], the United States [29] and the United Kingdom [30]. Given the increasing role of KM in upgrading business competitiveness, the wide interest of managers in measuring and evaluating both KM performance and benefit is not surprising [8].

At another level of analysis, the productivity paradox has become a contentious issue among both economists and the information technology (IT) community [7] [28]. Indeed, many KM practitioners have used IT to practice KM in form of a knowledge management system (KMS). Unfortunately, several researches indicate that while the level of IT investment is correlated to corporate revenues, it is not correlated to either productivity or profitability [11] [15]. Managers have found it difficult to demonstrate tangible returns on the resources expended to plan, develop, implement and operate KM. For example, since effectiveness and innovation cannot be readily quantified in 
terms of traditional outputs, these improvements are not reflected in economic efficiency statistics. Certainly, the fundamental issue of measuring and evaluating KM investments and performance remains unresolved.

This paper aims at proposing option pricing models in such a way that they become part of the managerial practice when evaluating KM solution. Its main contribution is the description of a real-life case study that demonstrates the usage of option valuation methods for analyzing KM. Regarding the organization of this paper; we start by giving an overview of prior research on KM evaluation in Section 2. We then describe the methodology of KM evaluation and integrate with balanced scorecard (BSC) in Section 3. Section 4 briefs on how the option models can serve as an evaluation tools for KM managers. The above-mentioned case study is presented in section 5. Finally, the conclusion and future work are discussed in Section 6.

\section{Preliminary}

KPMG [22] reports that the reasons for the creation of knowledge management initiatives cited by most companies are facilitating better decision making, increasing profit, and reducing costs. However, KM suffers from the same challenges as many other management issues: it assumes that knowledge is a 'thing' which is amenable to being 'managed' by a 'manager'. First, which KM process is the key point to achieve competitive advantage? Second, which measurement method is the remarkable viewpoint to appraise KM performance?

KM performance measurement methods are broad category of research issues. We can see the method developments are diversified due to researchers' backgrounds, expertise, and problem domains [23]. In our research, we can classify KM evaluation methods according to three types: qualitative and quantitative, financial and nonfinancial, internal and external performance approaches.

\subsection{Qualitative and Quantitative Approach}

A qualitative research approach was refined using the outcomes of a pilot study and reviews by researchers of organization learning. For example, the success of knowledge sharing in organizations culture, are not only technological but also related to behavior factors. Besides, expert interviews, critical success factors method (CSFs), and questionnaires are used to implement qualitative methods for exploring specific human problem.

Table 1. The benefits in the qualitative and quantitative index

\begin{tabular}{|c|c|}
\hline \multicolumn{2}{|c|}{$\begin{array}{c}\text { Knowledge Management Benefits } \\
\end{array}$} \\
\hline Qualitative Index & Quantitative Index \\
\hline $\begin{array}{l}\text { - Improving employees skills } \\
\text { - Improving strategies quality } \\
\text { - Improving core business processes } \\
\text { - Developing customer relationship } \\
\text { - Developing supplier relationship } \\
\text { - Developing innovative cultures }\end{array}$ & $\begin{array}{l}\text { - Decreasing operation costs } \\
\text { - Decreasing product cycle time } \\
\text { - Increasing operation productivity } \\
\text { - Increasing market sharing } \\
\text { - Increasing shareholder equities } \\
\text { - Increasing patent income }\end{array}$ \\
\hline
\end{tabular}


In opposition, a quantitative research approach was designed to represent a tangible, visible and comparable 'ratio'. It can be measured by financial and non-financial index. We will discuss in next paragraph. Table 1 shows the KM benefits and classes with qualitative or quantitative indexes.

\subsection{Financial and Non-financial Approach}

Traditional quantitative methods focus on well-known financial measures, such as the payback period, the return on investment (ROI), the net present value (NPV), the return of knowledge (ROK), and the Tobin's q. These methods are best-suited to measure the value of daily transaction processing systems. Unfortunately, evaluation methods that rely on financial measures are not as well-suited for complicated IT applications. These systems typically seek to provide a wide range of benefits, including many that are intangible in nature. For example, it is difficult to quantify the full value of a point-of-sales (POS) system [4] or an enterprise resource planning (ERP) system [32].

Non-financial measures method is different from traditional financial statement analysis. It uses non-financial index, such as the frequencies, times, counts, and numbers. For example, the topic numbers of discuss board in KMS, are related to behavior factors and system usage situation.

\subsection{Internal and External Performance Approach}

Internal performance measurement methods focus on process efficiency and goal achievement efficiency. These methods evaluate KM performance through the gap between target and current value. The well-known methods are including ROI, NPV, balanced scored (BSC), and activity-based costing (ABC).

External performance measurement methods always compare itself with benchmark companies, primary competitions, or whole industry average. For example, benchmarking is the process of determining who is the very best, who sets the standard, and what that standard is. When we apply the benchmarking concept in business, the following types of questions are being asked: Which company has the best manufacturing operation? And how do we quantify that standard?

\subsection{Option Valuation Approach}

A number of researchers have written on the use of option models in IT investment decision making. The pioneering work of DosSantos [13] employs Margrabe's exchange option model [25] for valuing an IS project that uses a novel technology for testing. He argues the option model would be better than NPV to evaluate new IT project. Similarly, Kambil et al. [17] use the Cox-Rubinstein binomial option pricing model [10] to determine whether or not a pilot project should be undertaken.

For a software platform, several options usually are relevant. In analogy to Kester's "growth options" for firms [21], Taudes investigates options for evaluating "software growth option" [31], which can be valued software platforms and benefit.

Benaroch and Kauffman [4] investigate the problem of investment timing using the Black-Scholes model in a real world case study dealing with the development of point-of-sale (POS) debit service. Their contributions are not whether an investment 
should be undertaken, but when to exercise the option held, i.e., when to implement a particular IT solution. In a follow-up paper, Benaroch and Kauffman [5] use sensitivity analysis to probe Black-Scholes valuation for IT investment opportunities. Taudes et al. [32] also compare NPV with Black-Scholes valuation method for employing SAP R/2 or to switch to SAP R/3. These results also indicated that, in the absence of formal evaluation of the time option, traditional approaches for evaluating information technology investments would have produced wrong recommendations.

\section{Method and Evaluation Design}

A universally accepted definition of KM does not yet exist. While there is debate as to whether knowledge itself is a cognitive state, a process, an object, the description of $\mathrm{KM}$ as a process, based on understanding organization as a knowledge system [14]. This view examines the nature of individual knowledge and collective knowledge, and their interactions.

\subsection{The Methodology of KM Evaluation}

While authors differ in the terminology used in describing the KM process, the aggregate of their works can be described as a simple KM process as depicted in Fig.1. We generalized a conclusion from a collection of related KM researches and defined the "4C" process of KM activities: creation, conversion, circulation, and carry out.

Knowledge creation relates to knowledge addition and the correction of existing knowledge. Nonaka and Takeuchi [27] suggest four modes of knowledge creation: socialization, externalization, internalization, and combination. The model emphasizes interactions between individuals and organizations.

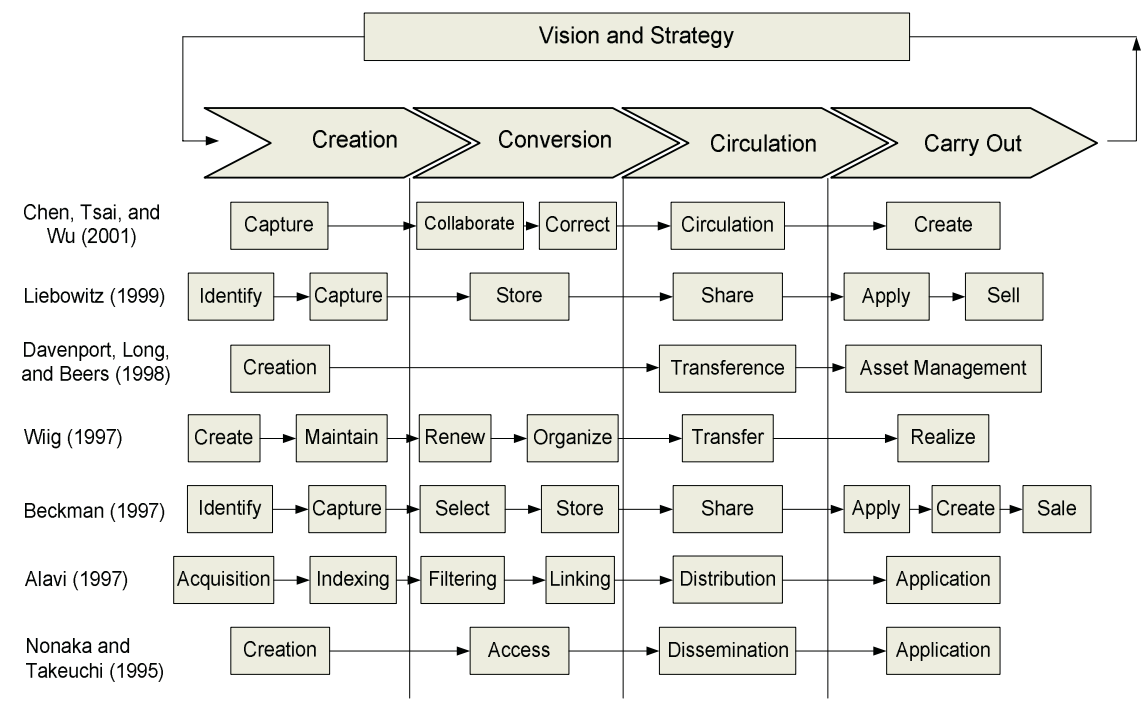

Fig. 1. KM process (see [2] [3] [9] [12] [24] [27] [33]) 
Knowledge conversion relates to individual and organizational memory. While organizational memory reflects the shared interpretation of social interactions, individual memory depends on the individual's experiences and observations.

Knowledge circulation is the dyadic exchange of knowledge between source and receiver. Transfer occurs at various levels: Transfer of knowledge between individuals, form individuals to explicit sources, form individuals to groups, between groups, across groups, and from the groups to the organization.

An import aspect of the knowledge carry out is that the source of competitive advantage resides in the knowledge itself. Here a major challenge is how to integrate internal knowledge and the knowledge gained from outside.

In order to present important research issues the pursuit of which would lead to the enhancement of knowledge usage in an organization, research questions related to each step of KM process can be integrated into four perspectives with BSC framework.

\subsection{The Integration with BSC Framework}

Underlying Kaplan and Norton's [18,19,20] concept of the BSC is that all aspects of measurement have their drawbacks; however, if companies offset some of the drawbacks of some measures with the advantages of others, the net measure can lead to decisions resulting in both short term profitability and long term success. As a result, they suggest that financial measures be supplemented with additional ones that reflect customer satisfaction, internal business processes, and the ability to learn and grow.

In a BSC framework, there are some metrics that drives performance improvement and enables the top management team to make well-informed decisions that prepare their organization for the future. The major elements are including: (1) vision: an image of what the organization will look like and do in the future; (2) strategy: that gives a sense of purpose to their organization; (3) objectives: the mission and vision are translated into objectives; (4) performance measures: the objectives can be measured through well-chosen indicators. Table 2 outlines the four perspectives included in a balanced scorecard, and Fig.2 shows the relationships between them.

The BSC concept can also be applied to measure, evaluate and guide activities that take place in specific functional areas of a business. For this reason, we integrated the conception of BSC and 4C process of KM.

The following four perspectives have been suggested for a balanced KM scorecard: creation, conversion, circulation, and carry out. The relationship between these four new perspectives is illustrated in Fig.3.

Table 2. The four perspectives in a BSC

\begin{tabular}{|l|l|}
\hline \multicolumn{1}{|c|}{ Perspective } & \multicolumn{1}{c|}{ Mission } \\
\hline Financial & $\begin{array}{l}\text { To focus on the themes of (1) revenue growth and mix, (2) cost reduc- } \\
\text { tion and profitability, and (3) asset utilization and investment strategy. }\end{array}$ \\
\hline Customer & $\begin{array}{l}\text { To achieve desired overall performance, by improving customers' } \\
\text { satisfaction, retention, and acquisition rate. }\end{array}$ \\
\hline Internal Business & $\begin{array}{l}\text { To identify processes those are most critical for achieving customer } \\
\text { and ownership objectives, i.e., quality, cycle time, and innovation. }\end{array}$ \\
\hline $\begin{array}{l}\text { Growth and } \\
\text { Learning }\end{array}$ & $\begin{array}{l}\text { To identify needed developments within the organization to provide } \\
\text { the infrastructure for future growth, i.e., employee capabilities, pro- } \\
\text { ductivity, and empowerment. }\end{array}$ \\
\hline
\end{tabular}




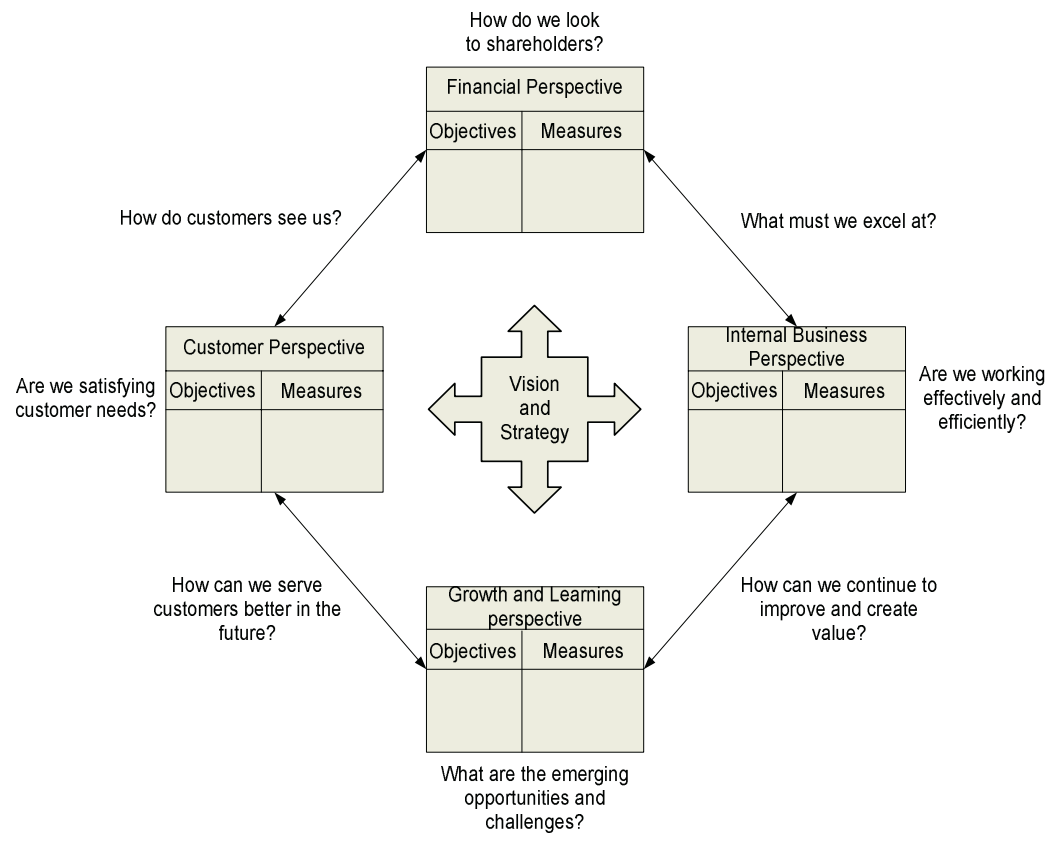

Fig. 2. Relationship between the four perspectives in the BSC

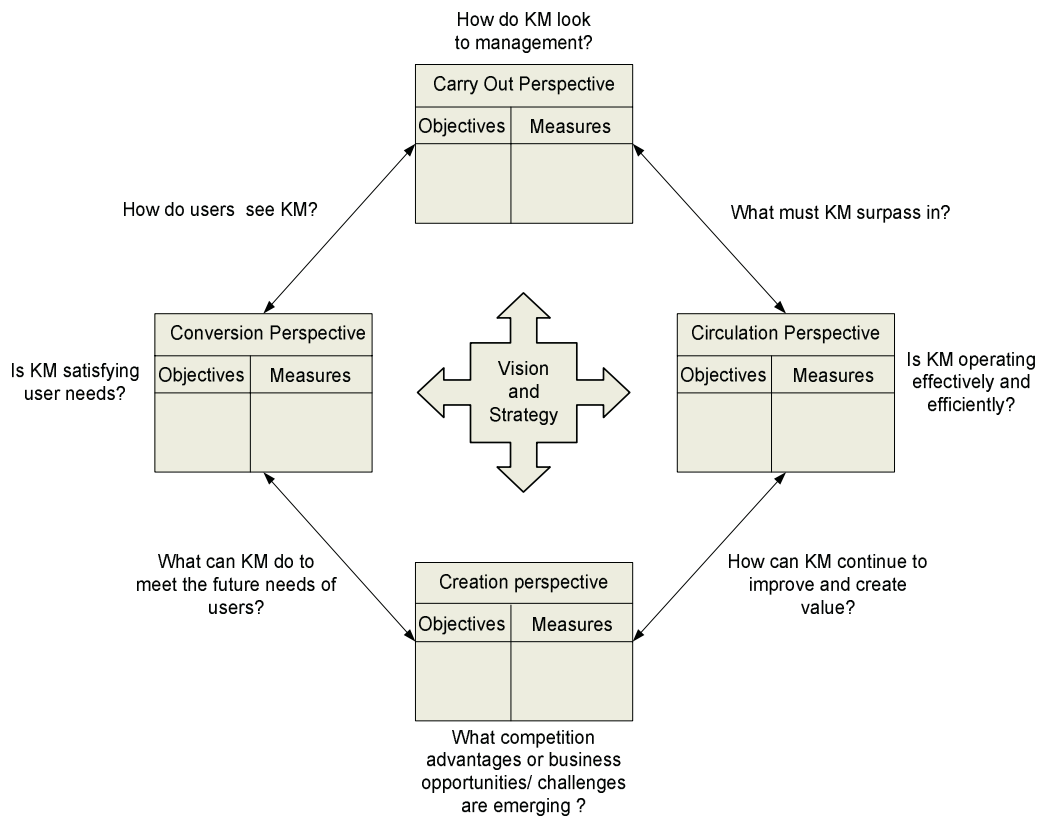

Fig. 3. Relationship between the four perspectives in the balanced KM scorecard 


\section{Applying the Black-Scholes Model}

The field of finance has developed a variety of option pricing models, with the fundamental ones being the Black-Scholes model. Because these models were originally developed to evaluate options on securities traded in the financial markets, they make certain assumptions that more naturally apply to options on traded assets. Over time, these models and their extensions have also been used in a variety of evaluative settings involving capital budgeting investments embedding real option. This pape makes three important contributions in this context: (1) it provides a formal theoretical grounding for the validity of the Black-Scholes model that might be employed toKM; (2) it proposes a measurement framework to enable leveraging knowledge assets effectively and efficiently; (3) it presents the first application of the BlackScholes model that uses a real world business situation involving KM as its test bed.

\subsection{Fundamental Option Pricing Model}

In section 2, we sought a range of issues for KM valuation. Consequently, the key to understanding the KM performance evaluation in which option pricing is worthwhile to use relates to basic elements of the Black-Scholes model. For example:

(1) KM infrastructure investments often are made without any immediate expectation of payback. However, these can be converted investment opportunities into the option's underlying asset. Some examples of these investments include intranet and Internet environment, data warehousing and data mining technologies, and web service.

(2) KM embedded technologies are often difficult to forecast value payoffs in the face of unpredictable, implementation, and maintenances costs. Some examples of these technologies include search engine, enterprise information portal, and automated workflow systems.

(3) Knowledge investments represent that the knowledge is a core part of a company's competition advantages. Therefore, knowledge can be viewed as a product and gain tangible or intangible profits. Nevertheless, the knowledge has its "product life cycle" through newborn, mature, and abandoned phase. Here, the knowledge usage conception is similar to option pricing as time remaining to exercise.

\subsection{Assumption About Black-Scholes Model}

The Black-Scholes option pricing formula [6] prices European call or put options on a stock that does not pay a dividend or make other distributions. The formula assumes the underlying stock price follows a geometric Brownian motion with constant volatility.

(1) The Definition of Black-Scholes formula

$$
\text { Option pricing formula prices }=\text { Intrinsic Value }+ \text { Time Value }
$$

Equation (1) can be explained that perfect financial markets are arbitrage-free in the sense that no investor can make a profit without taking some risk or expending some capital. Such gains could be made if an option were priced differently than a portfolio consisting of the underlying asset and a risk-less security with the amounts 
being continuously adjusted so that the value of the portfolio replicates the value of the option. In equation (1), the value of a company or an asset based on an underlying perception of the value is called intrinsic value. For call options, this is the difference between the underlying stock price and the strike price; and further, time value is represented the portion of the option premium that is attributable to the amount of time remaining until the expiration of the option contract. Basically, time value is the value the option has in addition to its intrinsic value.

(2) Applying the Black-Scholes formula

In the Black-Scholes model [16], the value of a call option is its discounted expected terminal value, $\mathrm{E}\left[C_{T}\right]$. The current value of a call option is given by $C=E\left[C_{T}\right](1+r)^{-t}$, where $(1+r)^{-t}$ is the present value factor for risk-neutral investors. A risk-neutral investors is indifferent between an investment with a certain rate of return and an investment with an uncertain rate if return whose expected vale matched that of the investment with the certain rate of return. Given that $C_{T}=\max [0$, $\left.S_{T}-\mathrm{K}\right]$, and assuming that $S_{T}$ is log-normally distributed, it can be shown that:

$$
\text { Black-Scholes formula: } C=S \cdot \Phi\left(d_{1}\right)-K(1+r)^{-t} \Phi\left(d_{2}\right)
$$

where

$$
\begin{aligned}
& d_{1}=\frac{\ln \frac{S}{K}+\left(r+0.5 \sigma^{2}\right) t}{\sqrt[\sigma]{t}} \\
& d_{2}=\frac{\ln \frac{S}{K}+\left(r-0.5 \sigma^{2}\right) t}{\sqrt[\sigma]{t}}=d_{1}-\sqrt[\sigma]{t}
\end{aligned}
$$

As shown in Equation (2), the Black-Scholes formula contains fewer parameters that are easier to determine. In addition to "ease to use" issue, applying option pricing concepts is attractive because of the conceptual clarity it brings to the analysis. Many knowledge management initiatives indicate the high potential variance of expected revenues from $\mathrm{KM}$ would be the key element in making the right decision. In this sense, option pricing seemed just right. We assume parameters of Black-Scholes

\begin{tabular}{|c|c|c|}
\hline Notation & Black-Scholes Option Pricing Model & Apply to KM \\
\hline $\mathrm{C}$ & The theoretical call premium & Value of investment \\
\hline$S$ & The value of option's underlying stock price & Value of expected revenues \\
\hline$K$ & The option's exercise price & Actual costs / expenses \\
\hline ó & $\begin{array}{c}\text { The standard deviation of the expected rate of } \\
\text { return on } S\end{array}$ & Uncertain factors \\
\hline$\Phi\left(d_{1}\right)$ & $\begin{array}{l}\text { The exposure of the option price with respect } \\
\text { to the stock price }\end{array}$ & $\begin{array}{l}\text { Measurement of KM in- } \\
\text { vestment and output }\end{array}$ \\
\hline$\Phi\left(d_{2}\right)$ & $\begin{array}{l}\text { The cumulative standard normal distribution } \\
\text { evaluated at }(\mathrm{S}>\mathrm{K}) \text { or }(\mathrm{S}<\mathrm{K})\end{array}$ & $\begin{array}{l}\text { Probability of KM success } \\
\text { or fail }\end{array}$ \\
\hline
\end{tabular}
model to be applied for KM. We employ the following notation in Table 3.

Table 3. The notations for Black-Scholes option pricing model and apply to KM 


\section{Case Study}

In this paper, we use case study methodology to evaluate the performance of option pricing model, quite a lot of tests are preformed. To demonstrate how the test was executed, one experiment which is involves one high-technical company was selected and the research process as shown in Fig.4.

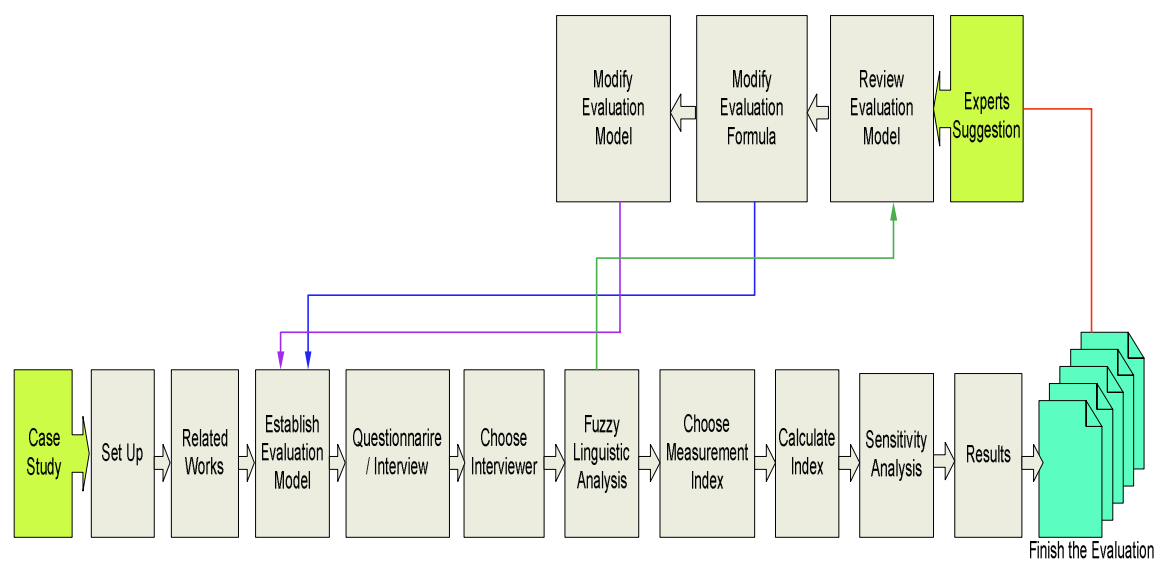

Fig. 4. Case study research process

\subsection{General KM Evaluation}

In order to acquire the importance for each measure in proposed four perspectives balanced KM scorecard, we design a questionnaire and interview end-users. Additional, we use fuzzy linguistic analysis to decide the default value for importance in each measure.

(1) The questionnaire analysis

In this questionnaire survey, 74 questionnaires were sent, 60 valid questionnaires were retrieved, and the ratio of valid retrieves was $81 \%$.

(2) Setting up triangular fuzzy number

We used fuzzy Delphi method to adjust the fuzzy weight value for each measure. Then, we calculated the triangular fuzzy number for each measure. For example, the final measure of "innovation ability" in knowledge creation perspective was described as follows.

$$
\begin{aligned}
& \tilde{W}_{\text {innovation }}=(0.2,0.61,0.9) \\
& a_{\text {innovation }}=0.2 \\
& b_{\text {innovation }}=1 / 60[(14 * 0.8)+(9 * 0.3)+(11 * 0.75)+(22 * 0.5)+(4 * 0.9)]=0.6125 \\
& c_{\text {innovation }=0.9}
\end{aligned}
$$


Where $\tilde{W}=\left(a_{k}, b_{k}, c_{k}\right), k=1,2, \ldots . n$

$$
a_{k}=\operatorname{Min}_{l}\left\{a_{l k}\right\}, \quad b_{k}=\frac{1}{m} \sum_{l=1}^{m} b_{l k}, \quad c_{k}=\operatorname{Max}_{l}\left\{c_{l k}\right\}
$$

As shown in Equation (3), $\tilde{W}$ represents the $k^{\text {th }}$ measure's importance of the $l^{\text {th }}$ participation's valuation.

(3) Averaging the evaluation measures

After above step, we average each fuzzy weight value $\tilde{W}_{k}$, and get the mean value $S_{k}$. For example, the mean value $S_{k}$ of "innovation ability" in knowledge creation perspective was described as follows. Table 4 shows an example of four perspectives measures value.

$$
S_{\text {innvoation }}=\frac{0.2+0.61+0.9}{3}=0.57
$$

According to the results, we can understand the KM performance in each perspective. However, we cannot gather significant discoveries because of there are not differentiable measure values in Table 4. Therefore, we will use our proposed option pricing model to estimate $\mathrm{KM}$ performance for each perspective.

\subsection{Using Black-Scholes Option Pricing Model}

In this section, we use Black-Scholes model to estimate knowledge creation perspective as an example. In Equation (4) (6), we use parameters of Black-Scholes model to calculate the appropriate value which can be represented total key performance index (KPI). Even as Equation (7), we can determine which KM process or perspective must to be improved by KPI. As shown in Table 5, the knowledge carry out process is the most weakness in whole $\mathrm{KM}$ activities ( $\mathrm{PKI}=0.0014$ ). Therefore, the manager will enhance related objectives in this perspective according to the above statement.

(1) Calculating the investment costs of $\mathrm{KM}(S)$

$S_{K M}=\sum_{1}^{t} C_{K M}=($ equipment $\cos t+$ labor $\cos t+$ time $\cos t+$ operation $\cos t)$

(2) Calculating the expected revenues of $\mathrm{KM}(K)$

$$
K_{K M}=\sum_{1}^{t} R_{K M}=\left(\begin{array}{lll}
\text { physical } & \text { revenues }+ \text { invisible revenues }
\end{array}\right)
$$

(3) Calculating the uncertain factors $(\sigma)$

$$
\sqrt{\sum_{i=1}^{n} \frac{\left(S_{i}-\overline{S_{K M}}\right)^{2}}{n}}, S_{i}=S_{K M}(t)-S_{K M}(t-1)
$$

(4) Calculating the total key performance index (KPI)

$$
\begin{gathered}
B S_{K M} \text { value }=K P I \\
K P I=C=S \cdot \Phi\left(d_{1}\right)-K(1+r)^{-t} \Phi\left(d_{2}\right)
\end{gathered}
$$


Table 4. The value of four perspectives in a balanced KM scorecard

\begin{tabular}{|c|c|c|c|}
\hline KM Process & $\begin{array}{c}\text { Objective } \\
\end{array}$ & Measure & Value \\
\hline \multirow{3}{*}{ Creation } & Continuously training and development & 0.64 & \multirow{3}{*}{0.65} \\
\hline & The innovation abilities for users & 0.57 & \\
\hline & The average seniority for users & 0.73 & \\
\hline \multirow{3}{*}{ Conversion } & Users' experiences & 0.62 & \multirow{3}{*}{0.54} \\
\hline & Users' professional skills & 0.48 & \\
\hline & User's satisfaction & 0.52 & \\
\hline \multirow{3}{*}{ Circulation } & The incentive systems for users & 0.55 & \multirow{3}{*}{0.54} \\
\hline & The sharing culture among users & 0.57 & \\
\hline & The standardization of documents & 0.51 & \\
\hline \multirow{3}{*}{ Carry Out } & Ensure the KM project provides business value & 0.62 & \multirow{3}{*}{0.51} \\
\hline & The quantities / qualities of knowledge database & 0.42 & \\
\hline & The numbers of patents & 0.50 & \\
\hline
\end{tabular}

Table 5. KPI of Black-Scholes model

\begin{tabular}{|c|c|c|c|c|c|}
\hline \multirow{2}{*}{ KM Process } & \multicolumn{2}{|c|}{$\begin{array}{c}\text { Intrinsic value } \\
\text { (S-K) }\end{array}$} & \multicolumn{2}{c|}{ Time value } & \multirow{2}{*}{$\begin{array}{c}\text { Black-Scholes } \\
\text { option value }\end{array}$} \\
\cline { 2 - 5 } & $\mathbf{S}$ & $\mathbf{K}$ & $\boldsymbol{\sigma}$ & $\boldsymbol{t}$ & \\
\hline Creation & 2400 & 3215 & $12 \%$ & 2 & 35.8174 \\
\hline Conversion & 2150 & 3000 & $12 \%$ & 2 & 20.2288 \\
\hline Circulation & 2000 & 3400 & $12 \%$ & 2 & 1.0652 \\
\hline Carry out & 2000 & 4600 & $12 \%$ & 2 & $\mathbf{0 . 0 0 1 4}$ \\
\hline
\end{tabular}

\subsection{Sensitivity Analysis Using Black-Scholes Model Derivatives}

Sensitivity Analysis aims at showing how the results of an analysis change as its underlying assumptions change. As shown in Table 6, we can evaluate the benefits or costs in the KM project with derivative analysis.

Table 6. Sensitivity Analysis

\begin{tabular}{|l|l|l|l|l|l|}
\hline \multicolumn{1}{|c|}{ KM Process } & \multicolumn{1}{c|}{ (Delta) } & \multicolumn{1}{c|}{ (Gamma) } & \multicolumn{1}{c|}{ (Vega) } & \multicolumn{1}{c|}{ (Theta) } & \multicolumn{1}{c|}{ (Rho) } \\
\hline Creation & 0.176 & 0.0006 & 878.0326 & -49.5336 & 773.0867 \\
\hline Conversion & 0.1208 & 0.0006 & 611.0055 & -32.6966 & 478.8825 \\
\hline Circulation & 0.0098 & 0.0001 & 73.9137 & -3.3267 & 36.9776 \\
\hline Carry out & 0.0 & 0.0 & 0.2634 & -0.0093 & 0.0744 \\
\hline
\end{tabular}

A major challenge for KM research lies in making models and theories to evaluation its performance and values. However, traditional methodologies have long relied on NPV, simple cost-benefit analysis, critical success factors and other less-structured techniques to perform their assessment. Thus, our experiment has been to critically 
review the case for using option pricing as a basis for KM performance analysis and to evaluate its merits in an actual real word business setting.

\section{Conclusions}

In this paper, we have made the argument the option pricing model can be applied to $\mathrm{KM}$ performance valuation. In the initial stage, we generalized a conclusion from a collection of related KM researches and defined the 4C process of KM activities: creation, conversion, circulation, and carry out. In the next stage, we pursuit of which process would lead to the enhancement of KM performance in a firm, hence we integrated $\mathrm{KM}$ process into four interrelated main research streams with BSC framework. Finally, we illustrated how the Black-Scholes model can be applied in the case of a real world KM performance option, where significant uncertainties that are not appropriately handled using traditional financial analysis were present. The results have proven the option pricing model can be act as a measurement guideline to the whole KM activities.

Future research will focus on several issues. First, we will investigate other firms into KM performance valuation by our approach. Second, we will gauge the risk associated with the KM project in a firm. Finally, we will improve the estimation parameters methods. Especially, more general guidelines could make the option valuation of KM performance less time-consuming and more reliable.

\section{References}

1. Ahn, J.H., and Chang, S.G.: Assessing the Contribution of Knowledge to Business Performance: the KP3 Methodology. Decision Support Systems, Vol. 36 (2004) 403 - 416

2. Alavi, M. KPMG Peat Marwick U.S.: One Giant Brain. Harvard Business School(Case), 9- 397- 108 (1997)

3. Beckman, T.: A Methodology for Knowledge Management. Proceeding of the IASTED International Conference on AI and Soft Computing (1997)

4. Benaroch M. and Kauffman R.J.: A Case for Using Real Options Pricing Analysis to Evaluate Information Technology Project Investments. Information Systems Research, Vol. 10, Iss. 1 (1999) 70-86

5. Benaroch M., and Kauffman R.J.: Justifying Electronic Banking Network Expansion Using Real Options Analysis. MIS Quarterly, Vol. 24, Iss. 2 (2000) 197-225

6. Black, F., and Scholes, M.: The Pricing of Options and Corporate Liabilities. Journal of Political Economy, Vol. 81, No. 3 (1973) 637-659

7. Brynjolfsson, E. and Hitt, L.: Paradox Lost? Firm-level Evidence on the Returns to Information Systems Spending. Management Science, Vol. 42, Iss. 4 (1996) 541-558

8. Brynjolfsson E., Renshaw, A.A., Alstyne, M.V.: The Matrix of Change. Sloan Management Review, Vol. 38, No.2 (1997) 37-54

9. Chen, M.Y., Tsai, M.J., and Wu, H.R.: The Research of KM Operation Module in Science \& Technology Industry - Case Study of TSMC. Proceedings of the 12th International Information Management Conference, Taiwan (2001) A-75

10. Cox, J., Ross, S., and Rubinstein, M.: Option Pricing: A Simplified Approach. Journal of Financial Economics, Vol. 6 (1979) 229-263

11. Das, A.: Knowledge and Productivity in Technical Support Work. Management Science, Vol. 49, Iss. 4 (2003) 416-431 
12. Davenport, T.H., Long, D.W., and Beers, M.C.: Successful Knowledge Management Projects. Sloan Management Review, Vol. 39, No. 2 (1998) 43-57

13. DosSantos, B.L.: Justifying Investments in New Information Technologies. Journal of Management Information Systems, Vol. 7, Iss. 4 (1991) 71-90

14. Grant, R.M.: Prospering in Dynamically-Competitive Environments: Organizational Capability as Knowledge integration. Organization Science, Vol. 7, No. 4 (1996) 375-387.

15. Holsapple, C.W., and Singh, M.: The Knowledge Chain Model: Activities for Competitiveness. Expert Systems with Applications, Vol. 20 (2001) 77-98

16. Hull, J.C.: Options, Futures, and Other Derivative Securities ( $2^{\text {nd }}$ edition). Prentice Hall, Englewood Cliffs, NJ (1993)

17. Kambil, A., Henderson, J., and Mohsenzaden, H.: Strategic Management of Information Technology Investments: An Option Perspective. in Strategic Information Technology Management: Perspectives on Organization Growth and Competitive Advantage, Idea Publishing Group (1993) 161-178

18. Kaplan R., Norton, D.: The Balanced Scorecard: Measures that Drive Performance. Harvard Business Review, Vol. 70, No. 1 (1992) 71-79

19. Kaplan R., Norton, D.: Putting the Balanced Scorecard to Work. Harvard Business Review, Vol. 71, No. 5 (1993) 134-142

20. Kaplan R., Norton, D.: Using the Balanced Scorecard as a Strategic Management System. Harvard Business Review, Vol. 74, No. 1 (1996) 75-85

21. Kester, W.C.: Today's Options for Tomorrow's Growth. Harvard Business Review, Vol. 62 (1984) 153-161

22. KPMG.: Knowledge Management Research Report, (1998) URL: http://www.kpmg.com

23. Liao, S.H.: Knowledge Management Technologies and Applications-Literature Review from 1995 to 2002. Expert Systems with Applications, Vol. 25 (2003) 155-164

24. Liebowitz, J.: Key Ingredients to the Success of an Organization's Knowledge Management Strategy. Knowledge and Process Management, Vol. 6, No. 1 (1999) 37-40

25. Margrabe, W.: The Value of an Option to Exchange One Asset for Another. Journal of Finance, Vol. 33, No. 1 (1978) 177-186

26. Nonaka, I.: The Knowledge Creating Company. Harvard Business Review, Vol. 69, No. 6 (1991) 96-104

27. Nonaka, I and Takeuchi, H.: The Knowledge Creating Company. New York, NY: Oxford University Press (1995)

28. Pinsonneault, A. and Rivard, S.: Information Technology and the Nature of Managerial work: From the Productivity Paradox to the Icarus Paradox. MIS Quarterly, Vol. 22, Iss. 3 (1998) 287-311

29. Schultze, U. and Leidner, D.E.: Studying Knowledge Management in Information Systems Research: Discourses and Theoretical Assumptions. MIS Quarterly, Vol. 26, No. 3 (2002) 213-242

30. Shin, M., Holden, T., and Schmidt, R.A.: From Knowledge Theory to Management Practice: Towards an Integrated Approach. Information Processing and Management, Vol. 37 (2001) 335-355

31. Taudes, A.: Software Growth Options. Journal of Management Information Systems, Vol. 15, Iss. 1 (1998) 165-185

32. Taudes, A., Feurstein, M. and Mild, A.: Options Analysis of Software Platform Decisions: A Case Study. MIS Quarterly, Vol. 24, Iss. 2 (2000) 227-243

33. Wiig, K.: Knowledge Management: Where Did It Come From and Where Will It Go. Expert Systems with Applications, Vol. 13, No. 1 (1997) 1-14 